\title{
Identifying synergies in Civil Technology practical activities and Engineering Graphics and Design in a University Technology Course in South Africa
}

\author{
Maeko Mogale Simon Albert ${ }^{\# 1}$, Khoza Samuel Dumazi ${ }^{* 2}$ \\ \# Durban University of Technology- School of Education Department, 15 F.J Sithole Road, Imbali, \\ Pietermaritzburg, 3201, South Africa \\ 1'maekos@dut.ac.za \\ *University of the Witwatersrand-Technology Education Department \\ 27 St Andrews Road Parktown, Johannesburg, South Africa \\ 2samuel.khoza@wits.ac.za
}

\begin{abstract}
Engineering Graphics and Design (EGD) is a compulsory subject that pre-service teachers in Technology Education take in South African Universities and it is often paired with Mechanical/ Electrical/ Civil and or Information Technology. The study used a mixed method approach and it was conducted to forty University's pre-service students who had Civil Technology (CT) as their majors who were selected using purposive sampling procedure. Questionnaire data was analyzed statistically using the SPSS software and interview data was analyzed descriptively using themes derived from quotes and narratives. Findings elucidate that CT practical activities do play a role towards learning EGD. Preservice teachers also said that they find it easier to use drawing models in learning CT lessons. The study then recommends that a thorough and relevant technical pedagogy be developed towards the teaching and learning of CT and EGD.
\end{abstract}

Keyword - Civil Technology, Engineering Graphics and Design, practical skills, pre-service teachers

\section{INTRODUCTION}

Civil Technology (CT) as a subject was introduced in 2004 as part of the National Curriculum Statement (NCS) in South African schools. However, to improve its implementation, the NCS was amended, giving birth to the development of CT national Curriculum and Assessment Policy Statement (CAPS) grades 10-12, with the amendments coming into effect in January 2012. The CAPS document is a policy document that is aimed at addressing the education challenges in South African education system from theoretically based to practically enhanced learning across the schools' sectors. The document outlines the detailing facts on each subject that it addresses and the weight values of each concept as well as the types of tasks that appear in that particular subject. The CT CAPS focuses on a combination of Construction, Civil Services and Woodworking and embraces both the practical skills and the application of the technological process. Civil Technology advocates' sound technical base that integrates both theory and practical competencies [4]. The importance of CT underpins the development of the built environment in a country through essential services such as roads, bridges, water purification, waterborne sewage, railway lines, high rise buildings, factories and housing in general [10]. Some of the skills that need to be honed and developed through the integrated completion of the theory and the practical are workshop practice, safe working practices and housekeeping. A workshop is a teaching and learning arena where sustainable economic skills should be nurtured and is critical for any quality practical hands-on activities to take place [1]. Most of the materials used in CT practical activities are wood because they are cheap and easily available. In addition, for students to learn and acquire skills in roads, bridges, water purification, waterborne sewage, railway lines, high raise buildings, factories and housing, they need a skill of drawing which is learnt in EGD in order for them to be able to design such structures mentioned. EGD provides students with the opportunity to communicate ideas graphically, carry out practical projects and tasks using the technological process [11]. According to [11], EGD requires the understanding of various line-types for students to have a better understanding when designing structures in Civil, Mechanical and or Electrical Technology through the applications of line-types. In addition, practical activities are compulsory for EGD and counts 25\% (100 marks) of the end-of-year examination mark [5]. The primary purpose of the EGD practical activities is to assess subjective content and concept topics which are not assessed in the examination papers. These are: the design process, the application of drawing knowledge and drawing skills to the design process, Computer Aided Draughting (CAD) management and drawings and the quality and neatness of free-hand, instrument and CAD drawings [5]. From the preceding points, it stands to reason that for teachers to engage with EGD and Civil Technology, they need to infuse practical activities. 
The EGD provides an accurate and complete picture for every object in terms of shape and size in the technology related fields [14]. The EGD emphasis is focused on the correct use of tools and equipment, drafting media, sketching, lettering, alphabet of lines, geometric construction, fundamentals of Computer Aided Draughting (CAD) and multi-view drawings. The two subjects, EGD and CT that this paper is all about have the enactment of practical activities in common. This is because Civil Technology and EGD are practical subjects, which needs certain skills in order to learn. Most projects that are designed and made in EGD are through wood because wood has been found to be easy to work with and the machinery that are used are found in the Civil Technology workshops which are also easy to use. Pre-service teachers who learn CT in South African Universities take EGD as their major and compulsory subject. In fact, EGD is a compulsory major subject to the University students who take Mechanical, Electrical, Civil and or Information Technologies. In a study that was conducted in one of the Universities in South Africa, it was found that pre-service teachers often battle with EGD because all what they draw is abstract [8]. Pre-service teachers complained about EGD being an abstract subject where they are expected to draw things like pipes/ pistons/ bridges etc. that they have never seen. Therefore, the enactment of practical activities into EGD plays a pivotal role in getting the teaching activities going. It is widely recognized that EGD drawings are the means of communication in the technology field [12]. This paper therefore focuses on the successes of infusing practical activities through CT to teach EGD.

\section{Facilitation of Civil Technology and Engineering Graphics and Design}

Practical work is teaching and learning activity that involves at some point the students observing or manipulating real objects and materials [16]. [16] concludes that practical work contrives learning experiences in which students interact with materials to check and observe phenomena in a practical workshop. In order to infuse theory and practice in engineering education, [14] opine that instruction should take place in the workshop or laboratory through lecture. [7] states that since the CT course is intended to be practically oriented, less theory should be taught. Simple explanations, sketches and descriptions should form the basis of the cognitive activities of this course. [9] suggests that teachers teaching practical subjects should determine ways and means to teach them as interesting subjects since they are practical. [13] recommends the following for stimulating interests and enjoyment in a practical subject:

a) Find ways to get students actively involved in the learning process.

b) Relate content objectives to student experiences.

c) Assess students' interests, hobbies and extra-curricular activities.

d) Use divergent questions and brainstorming activities to stimulate active involvement.

Therefore, we believe that by encouraging more practical activities in CT, students will be compelled to be hands-on in their activities, which in turn will require drawing basics for them to design CT projects that are learnt in their curriculum hence the intension of this paper.

\section{Purpose of the paper}

The study aimed at closing the existing gaps that the CT as well as the EGD South Africa's University preservice teachers has always experienced in learning the two said subjects. This is so because CT as a subject has concepts such as Construction, Plumbing, Bricklaying that cannot be facilitated without starting with mere sketches which emanates from drawings; a principle that makes EGD what it is. Therefore, we aimed at identifying factors that show synergies between CT and EGD to pre-service teachers in our Universities and the importance of why and how they can be facilitated and learnt.

\section{Problem statement and Research Questions}

CT is one of the practical subjects that aim at enhancing practical skills in Building, Built Engineering, Plastering as well as Bricklaying among other fields. On the other hand, EGD is a compulsory major subject that is paired with Civil Technology and other technologies in teacher training courses across Universities in South Africa. However, pre-service teachers had been performing poorly in EGD due to its abstract nature. In a study that was conducted previously in selected South African Universities, pre-service teachers complained that EGD is an abstract subject with no drawing models that ease its difficulty [9]. The said study [9] recommended that EGD needs to 'speak' to each Technologies that pre-service teachers take in order to have synergy. This was recommended in order to stop pre-service teachers from being reluctant to taking technical subjects in their degree course because of running away from EGD. Therefore, this paper aimed at investigating the extent of synergy between EGD and CT as a pair of major subjects that pre-service teachers in South African Universities take and the benefits thereof. The following research questions guided the study: 


\section{Main research question}

"What are the synergies between CT and EGD as major subjects in teacher education programmes in South African Universities”?

\section{Sub-research questions (RQs)}

RQ 1: What benefits do EGD and CT as paired major subjects offer to pre-service teachers during and after their degree completion?

RQ 2: Are there any similarities in learning EGD and CT concurrently?

\section{METHODOLOGY}

The study made use of both qualitative and quantitative methods to conduct. [10] describe a qualitative study as the study that aims for depth than quantity of understanding. According to [2], quantitative research method is about the investigator primarily using post-positivist claims for developing and employing strategies to collect statistical data by predetermined instruments, such as experiments and surveys. Qualitative and quantitative approaches as methods focus on collecting, analysing, and mixing both the data in a single study or series of studies [3]. Its central premise is that the use of quantitative and qualitative approaches, in combination, provides a better understanding of research problems than either approach alone.” This is so because one data resource may not be enough; initial results need to be further explained; a second method is needed to enhance a primary method.

Questionnaires were used as quantitative instruments to get responses to RQ's 1 and 2 (What benefits do EGD and CT as paired major subjects offer to pre-service teachers?) and Are there any similarities in learning EGD and CT concurrently? Whereas qualitative data was gathered through unstructured interviews to get responses to RQ 2 (Are there any similarities in learning EGD and CT concurrently?) Questionnaires were closed ended and were of a Likert scale type which only allowed pre-service teachers to tick one answer which ranged from SA, A, D, and SD where SA represented Strongly Agree and SD represented Strongly Disagreed. The interview was unstructured in order to allow the researchers to be flexible when asking questions. Part of the unstructured questions was as follows;

1. How significant is Civil Technology drawing models in your understanding of EGD concepts? Substantiate.

2. Do you think practical models help to reinforce theoretical concepts in both EGD and Civil Technology? Please add any further comments.

3. According to your own understanding, can you use your Civil Technology practical lesson to create a drawing model that can be used in an EGD class? Elaborate your response

On the other hand, quantitative data was analyzed statistically using the SPSS software in a way of finding comparisons of figures from pre-service responses. Qualitative data was analyzed descriptively as themes emerged from pre-service teachers from their responses. Forty pre-service teachers took part in the study and were selected using judgmental and convenient sampling. The participants, who were pre-service teachers, were from 4 different teacher-training universities in South Africa where Technology Education is offered. The reason we selected 10 from each university is that CT and EGD classes across the teacher-training universities in South Africa do not have a lot of students who specialize in CT and EGD as paired subjects, hence we used purposive sampling.

There were a total of 10 items that were tested through questionnaire and below is a table that shows the Cronbach's Alpha that was obtained that showed the reliability of the items.

TABLE 1: CRONBACH ALPHA VALUE

\begin{tabular}{|l|l|}
\hline Cronbach's Alpha & N of Items \\
\hline .65 & 10 \\
\hline
\end{tabular}

Table 1 shows that the Cronbach's alpha is 0,65 which falls between the scale of $0-1$. The alpha value falls within the scale of 0 to 1 and it proves that the 10 items that formed part of the questionnaire were reliable (Santos, 1999). The number of items represents the number of questions that were tested for reliability. The displayed alpha therefore proves that the instrument was reliable. 


\section{FINDINGS}

\section{QUESTIONNAIRE DATA}

Table 2: Questionnaire data for pre-service teachers

\begin{tabular}{|c|c|c|c|c|}
\hline Statement & Pre-servic & responses & $=40): F(\%$ & \\
\hline & SA & A & $\mathbf{D}$ & SD \\
\hline 1. Drawing models ease CT understanding & $18(45 \%)$ & $6(15 \%)$ & $12(30 \%)$ & $4(10 \%)$ \\
\hline $\begin{array}{llll}\text { 2. } & \text { Consistent CT practical helps EGD } \\
\text { understanding }\end{array}$ & $20(50 \%)$ & $10(25 \%)$ & $8(20 \%)$ & $2(5 \%)$ \\
\hline $\begin{array}{l}\text { 3. Less theory in CT is crucial towards EGD } \\
\text { success }\end{array}$ & $17(41 \%)$ & $11(28 \%)$ & $5(13 \%)$ & $7(18 \%)$ \\
\hline 4. $\quad$ EGD and CT complement each other & $25(63 \%)$ & $5(13 \%)$ & $8(20 \%)$ & $2(5 \%)$ \\
\hline $\begin{array}{l}\text { 5. Our workshop is well equipped for CT practical } \\
\text { lessons }\end{array}$ & $12(30 \%)$ & $8(20 \%)$ & $3(8 \%)$ & $17(42 \%)$ \\
\hline 6. We have sufficient drawing models for EGD & $8(20 \%)$ & $8(20 \%)$ & $11(28 \%)$ & $13(32 \%)$ \\
\hline $\begin{array}{l}\text { 7. I can confidently teach CT and EGD after } \\
\text { completing my course }\end{array}$ & $6(15 \%)$ & $9(23 \%)$ & $11(28 \%)$ & $14(34 \%)$ \\
\hline $\begin{array}{l}\text { 8. My CT marks are a reflection of my good } \\
\text { performance in EGD }\end{array}$ & $7(17 \%)$ & $5(13 \%)$ & $8(20 \%)$ & $20(50 \%)$ \\
\hline $\begin{array}{l}\text { 9. My EGD marks are a reflection of my good } \\
\text { performance in CT }\end{array}$ & $20(50 \%)$ & $8(20 \%)$ & $5(13 \%)$ & $7(\mathbf{1 7 \%})$ \\
\hline $\begin{array}{l}\text { 10. My drawing instruments are also user friendly } \\
\text { in CT subject }\end{array}$ & $15(38 \%)$ & $11(27 \%)$ & $4(10 \%)$ & $10(25 \%)$ \\
\hline
\end{tabular}

Table 2 served as questionnaire questions that were administered to EGD and CT pre-service teachers. The questionnaire was aimed at finding out the usefulness of EGD towards learning CT and vice versa. The $F$ on the table represents the frequency of respondents whereas the \% represents the percentage response of the preservice teachers. From the table above $60 \%$ of respondents agree that drawing models do help towards the understanding of CT with only $40 \%$ of the respondents having said drawing models do not make CT learning any easier. On the contrary, $47 \%$ of the respondents said consistent CT practical does not help towards learning EGD with only 53\% of their counterparts saying CT practical helps towards EGD. This is echoed by the $31 \%$ of the respondents that said more CT practical is crucial towards EGD in comparison to the $69 \%$ of their counterparts. On the other hand, the majority of the respondents (76\%) said CT and EGD complement each other. The issue of teaching EGD and CT confidently left much to be desired because $62 \%$ of the pre-service teachers said they are not confident to teach the two majors. On the other hand, $70 \%$ of the respondents said their CT marks are never boosted by the EGD performance with the other 30\% having said their CT marks are getting a fair boost from EGD.

The questionnaire data revealed that indeed CT and EGD complement each other. Pre-service teachers do believe that CT practical are much more relevant towards EGD learning and the EGD models that they have are helping in making them understand CT. The questionnaire findings revealed that EGD does provide students with the opportunity to communicate ideas graphically, carry out practical projects and tasks using the technological process skills of investigating, designing, making, evaluating and communicating [6] as discussed earlier in this study.

\section{Interview data}

There were two themes that emerged from RQ 2: Are there any similarities in learning EGD and CT concurrently? Most pre-service teachers agreed that EGD and Civil Technology complement each other and they make the best pairing subjects towards being a technical teacher. The two themes that were produced are: (1) Relevant drawing models towards Civil Technology makes learning of both majors easy to understand and (2) Civil Technology practical is important towards learning EGD. 


\section{Theme 1: Relevant drawing models towards Civil technology makes learning of both majors easy to understand}

Most pre-service teachers commended the use of drawing models that make it easier towards learning CT. One of the pre-service teachers in his fourth and final year of his degree course (Marvin) said the following: "I understand reading and drawing house plans much better when I first see a model of a house, this makes my understanding of house plans much easier". On the other hand, his classmate (Given) said: "I did not have a clue of what the drainage system looks like, I only had knowledge of it until my EGD lecturer took us to a construction site where a building was erected from scratch and that's when I got to understand what it meant". Another classmate of Given, Harry said: "At first it was difficult for me to read the drainage system line-work on the drawing until I saw it on a model that one of my classmates made, it is now clearer". In the meantime, a female second year student (Pauline) commented: "I had nightmares in understanding how a simple dwelling looks like in both single and double point perspective, until we were asked to build houses using boards in the workshop before drawing them, I love my subjects, I now have to concentrate on mastering how to teach them".

The above comments concur with what [18] said that practical work contrives learning experiences in which students interact with materials to check and observe phenomena in a practical workshop. This phenomenon assists students in mastering the content more practically. The comment that building a model before drawing helps in understanding EGD, proves that practical subjects should determine ways and means to teach them as interesting subjects since they are practical [9].

\section{Theme 2: Civil Technology practical is important towards learning EGD}

Theme 2 also complemented the notion that EGD enhances CT learning and understanding. A fourth year female student (Claire) said: "During our recent visit to a local construction site, I came to visualize how a foundation looks like and my comparison to how it looked practically and how it is in a drawing helped me to draw it with ease". Her University mate (Purity) echoed the same sentiment by saying: "How in the world was I going to know the difference between an elevation and a view? I wouldn't until I learnt house plans in my CT class". Another third year student (Paul) said: "Drawing a house in three dimensional was a nightmare from my first two years of my degree course until I learnt dwellings in CT classes, how incredible it is now, I can produce any dwelling in both perspectives". A fourth year male student (Emmanuel) said: "I can have the courage in pursuing a career in Built Engineering because of my drawing skills that I incorporate in CT practical classes, but as a future technical teacher, I believe I have what it takes to persuade my students to follow the said career upon their matric completion". These comments corroborate to what [11] said in this study that the importance of CT underpins the development of the built environment in a country through essential services such as roads, bridges, water purification, waterborne sewage, railway lines, high rise buildings, factories and housing in general, students become confident in seeing Civil Engineering from a more general and useful perspective.

\section{CONCLUSION AND RECOMMENDATIONS}

From the study, it is clear that the best way for the pre-service teachers to cope with CT and EGD is to start with concrete learning of EGD. This should be emphasized that drawing models are available in EGD lessons that do speak to CT contents. From the findings, it was evident that EGD have direct benefits to the learning CT and vice versa in a way that various line-types that are learnt in EGD, are clarified and better described in the practical applications of CT models in the CT content class. It was also found that there is a clear synergy between CT practical lessons and EGD. The similarities in both subjects are that they are both practical subjects and for anyone to design a bridge for example, they need to have learnt a particular skill of applying various suitable line types in and EGD class.

The study recommends that an EGD lecturer at the university needs to have a clear understanding of CT content in order to bring relevance in their EGD classes and the same should apply to CT lecturers about their knowledge of EGD. With 31\% of pre-service teachers calling for more CT practical lessons it really shows that more balance should be struck between CT and EGD because 76\% of the respondents agreed that CT and EGD complement each other. The study also recommends that a special pedagogical approach be developed in order to boost the confidence of pre-service teachers towards teaching EGD and CT. methodology classes should therefore emphasize pedagogical practices of both subjects in order to bring more confidence in pre-service teachers when teaching the two subjects. This is so because from the questionnaire response, only $38 \%$ of the respondents said they are confident in teaching the two subjects, which is not a good reflection of a technical teacher. The finding of the study also calls for pre-service trainers to be well aware with the Technologies that go hand in hand with EGD so that there is stimulation in the way of presentation and learning. What the preservice teachers learn and do in their CT classes should be escalated into their EGD classes and vice versa in order to keep up with the relevance of the two subjects. We therefore feel that failure to complement the pedagogical practices of the two subjects will result in the gap that has always existed in learning CT as well as EGD and other Technologies that go with EGD in South African universities. 


\section{ACKNOWLEDGMENT}

The authors of this paper would like to thank the pre-service teachers of the university in South Africa who made this paper possible by their participation.

\section{REFERENCES}

[1] Auta, M. S. A. (2015). Strategies for evaluation of students' proficiency in practical skills in NCE (Technical) building technology education. International Journal of Vocational and Technical Education, 7(9): 96-99.

[2] Creswell, J.W. (2003). Research Design Qualitative, Quantitative, and Mixed Methods Approaches. London: Sage Publications.

[3] Creswell, J. W., \& Plano Clark, V. L. (2011). Designing and conducting mixed methods research (2nd ed.). Thousand Oaks, CA: Sage Publications, Inc.

[4] Department of Basic Education. (2014). Curriculum Assessment Policy Statements (CAPS) - Civil Technology policy grade 10-12. Pretoria: Government Printing.

[5] Department of Basic Education. (2017). Engineering Graphics and Design (EGD)- guidelines for practical assessment tasks. Pretoria: Government Printing

[6] Department of Education, (2002). Gauteng Strategy for Mathematics, Science and Technology Education (2002- 2006): Promoting a Mathematically Powerful, Scientifically Literate and Technologically Fluent Society. Pretoria: Government Printers.

[7] Kennedy, O.O. (2011). Philosophical and Sociological Overview of Vocational and Technical Education in Nigeria. AmericanEurasian Journal of Scientific Research, 6(1): 52-57.

[8] Khoza, S.D. (2013). Difficulties in Sectional Drawing. A case of Student Teachers in a University based in the Eastern Cape. Unpublished PhD thesis. Tshwane University of Technology. Pretoria.

[9] Khoza, S.D. (2004). Academic performance of Engineering Drawing N2 students of Ekurhuleni West College in 2003. Unpublished Master's Dissertation. Tshwane University of Technology: Pretoria.

[10] Henning, A., Van Rensburg, W., \& Smit, B.2009.Finding your way in qualitative research. Pretoria: Van Schaik Publishers

[11] Maeko, M.S.A (2013). Practical Activities in Civil Technology: A Case study of Three Technical Schools in the Eastern Province. Unpublished Masters Dissertation. Tshwane University of Technology. Pretoria.

[12] Moolman, C.L. \& Brink, C.G. (2010). Engineering Drawing N3. 3rd ed.). Heinemann.

[13] Pillay, A.S \& Sotsaka, D.S. (2017). Engineering Graphics and Design Teacher’s Understanding and Teaching of Assembly Drawing. EURASIA Journal of Mathematics Science and Technology Education, 13(5):1213-1228.

[14] Prieto, G. \& Velasco A. 2002. Predicting Academic Success of Engineering Students in Technical Drawing from Visualization Test Scores: Heldermann Verlag.

[15] Raffini, J.P. (1996). 150 Ways to Increase Intrinsic Motivation in the Classroom. Whitewater: University of Wisconsin.

[16] Rosa, J. \& Feisel, L.D. (2005). The Role of the Laboratory in Undergraduate Engineering Education. Journal of Engineering Education. January 2005.

[17] Santos, J.R.A. (1999). Cronbach's alpha: a tool for assessing the reliability of scales. Journal of Extension, 37(2), 1- 5. Available from http://www.joe.org/joe/1999april/tt3.html

[18] Vilaythong, V. (2011). The Role of Practical Work in Physics Education in Lao PDR. Sweden: Print and Media, Umeå University.

[19] Widad, O. \& Adnan A. (2000). Teachers Thinking Style in Solving Engineering Drawing Problems. Proceedings of International Conference On Technical \& Vocational Education. 21-23 November 2000. Petaling Jaya: Institute.

\section{AUTHOR PROFILE}

Dr Maeko Mogale Simon Albert obtained National Diploma Technical Education, Baccalaureus Technologiae, Masters and Doctorate in Technology Education from the Tshwane University of Technology, South Africa. He also obtained his Bachelor of Education in Management and Policy from the Walter Sisulu University, South Africa. He has been engaged in teaching for a period of about 22 years, research for period of about 4 years. He is currently employed by the Durban University of Technology and facilitates Technology subjects to preservice teachers.

Dr Samuel Dumazi Khoza is currently employed at the University of the Witwatersrand in Parktown, Johannesburg, South Africa in the Technology Department, Division of Educational Information and Engineering Technology. He facilitates Technology subject as well as Engineering Graphics and Design to preservice teachers and also supervises post graduate students in Honours, Masters and PhD students 